\title{
KERNEL OPERATORS WITH VARIABLE INTERVALS OF INTEGRATION IN LEBESGUE SPACES AND APPLICATIONS
}

\author{
Vladimir D. Stepanov and Elena P. Ushakova
}

Abstract. New criteria of $L_{p}-L_{q}$ boundedness of Hardy-Steklov type operator (??) with both increasing on $(0, \infty)$ boundary functions $a(x)$ and $b(x)$ are obtained for $1<p \leqslant q<\infty$ and $0<q<p<\infty, p>1$. This result is applied for two-weighted $L_{p}-L_{q}$ characterization of the corresponding geometric Steklov operator (??) and other related problems.

Mathematics subject classification (2010): Primary 26D10; Secondary 26D15, 26 D07. Keywords and phrases: Integral operators, Lebesgue spaces, weights, boundedness.

\section{REFERENCES}

[1] Batuev, E.N., Weighted inequalities of Hardy type and applications, PhD Thesis, 1991, Khabarovsk University of Technology.

[2] Batuev, E.N.; Stepanov, V.D., On weighted inequalities of Hardy type, Siberian Math. J., 30 (1989), 8-16.

[3] Bloom, S.; Kerman, R., Weighted norm inequalities for operators of Hardy type, Proc. Amer. Math. Soc., 113 (1991), 135-141.

[4] BRadley, J.S., Hardy inequalities with mixed norms, Canad. Math. Bull., 21 (1978), 405-408.

[5] Chen, T.; Sinnamon, G., Generalized Hardy operators and normalizing measures, J. Ineq. Appl, 7 (2002), 829-866.

[6] Gogatishvili, A.; LAng, J., The generalized Hardy operators with kernel and variable integral limits in Banach function spaces, J. Inequal. Appl., 4 (1999), 1-16.

[7] Heinig, H.P.; Sinnamon, G., Mapping properties of integral averaging operators, Studia Math., 129 (1998), 157-177.

[8] Johansson, M.; Stepanov, V. D.; Ushakova, E.P., Hardy inequality with three measures on monotone functions, Math. Inequal. Appl., 11, 3 (2008), 393-413.

[9] Kufner, A.; Maligranda, L.; Persson, L.-E., The Hardy inequality. About its history and some related results, Vydavatelský Servis, Plzeň, 2007.

[10] Kufner, A.; Persson, L.-E., Weighted inequalities of Hardy type, World Scientific Publishing Co., Inc., River Edge, NJ, 2003.

[11] Lomakina, E.N.; Stepanov, V.D., On the Hardy-type integral operators in Banach function spaces, Publ. Mat., 42 (1998), 165-194.

[12] MaZ’YA V.G., Sobolev Spaces, Springer-Verlag, Berlin, 1985.

[13] Muckenhoupt, B., Hardy's inequality with weights, Studia Math., 44 (1972), 31-38.

[14] OpIC, B., Kufner, A., Hardy-type inequalities, Pitman Research Notes in Mathematics Series 219, Longman Scientific \& Technical, Harlow, 1990.

[15] Oinarov, R., On weighted norm inequalities with three weights, J. London Math. Soc., 48 (1993), 103-116.

[16] Oinarov, R., Two-sided estimates of the norm of some classes of integral operators, Proc. Steklov Inst. Math., 204, 3 (1994), 205-214.

[17] Persson, L.-E.; Prokhorov, D., Integral inequalities for some weighted geometric mean operator with variable limits, Arch. Ineq. Appl., 2 (2004), 475-482.

[18] Persson, L.-E.; StePAnov, V. D., Weighted integral inequalities with the geometric mean operator, J. Inequal. Appl., 7 (2002), 727-746. 
[19] Persson, L.-E.; StePanov, V. D.; Ushakova, E.P., Equivalence of Hardy-type inequalities with genelal measures on the cones of non-negative respective non-increasing functions, Proc. Amer. Math. Soc., 134, 8 (2006), 2363-2372.

[20] Prokhorov, D., Inequalities of Hardy type for a class of integral operators with measures, Anal. Math., 33 (2007), 199-225.

[21] SAWYER, E.T., Boundedness of classical operators on classical Lorentz spaces, Studia Math., 99 (1990), 135-158.

[22] Sinnamon, G., Hardy's inequality and monotonicity, Function spaces, Differential Operators and Nonlinear Analysis, Prague, 2005, pp. 292-310.

[23] Sinnamon, G.; Stepanov, V.D., The weighted Hardy inequality: new proofs and the case $p=1$, J. London Math. Soc., 54 (1996), 89-101.

[24] StEPAnOV, V.D. Integral operators on the cone of monotone functions, J. London Math. Soc., 1993, vol. 48 , pp. $465-487$.

[25] Stepanov, V.D., The weighted Hardy's inequality for nonincreasing functions, Tranc. Amer. Math. Soc., 338 (1993), 173-186.

[26] Stepanov, V.D., Weighted norm inequalities of Hardy type for the class of integral operators, J. London Math. Soc., 50 (1994), 105-120.

[27] Stepanov, V.D., Weighted norm inequalities for integral operators and related topics, Nonlinear analysis, function spaces and applications, Prague, 1994, vol. 5, pp. 139-175.

[28] Stepanov, V.D.; Ushakova, E.P., On integral operators with variable limits of integration, Proc. Steklov Inst. Math., 232 (2001), 290-309.

[29] Stepanov, V.D.; Ushakova, E.P., Hardy operator with variable limits on monotone functions, J. Funct. Spaces Appl., 1 (2003), 1-15.

[30] Stepanov, V.D.; Ushakova, E.P., On the geometric mean operator with variable limits of integration, Proc. Steklov Inst. Math., 260 (2008), 264-288.

[31] Tomaselli, G., A class of inequalities, Boll. Unione Mat. Ital., 2 (1969), 622-631. 